\title{
Ruthenium diphosphine complexes as an efficient hydroamination catalyst
}

\author{
Bahareh Tamaddoni Jahromi • Ali Nemati Kharat • \\ Mostafa M. Amini · Hamidreza Khavasi
}

Received: 15 March 2014/ Accepted: 19 August 2014/Published online: 10 January 2015

(C) The Author(s) 2014. This article is published with open access at Springerlink.com

\begin{abstract}
Ruthenium-catalyzed hydroamination of alkenes and alkynes with substituted anilines in the presence of various phosphine ligands have been investigated and catalyst activity and selectivity is improved. Ruthenium(II) complexes of diphenylphosphinomethane, diphenylphosphinoethane, diphenylphosphinopropane, diphenylphosphinobutane and diphenylphosphinopentane showed 50-90\% conversion under mild conditions. The effect of diphosphine ligands, substituent groups on anilines and reaction condition on the selectivity of hydroamination reaction were studied and the possible reaction mechanism was discussed. The reaction products were monitored by GC-MS and a mechanism for the hydroamination of alkenes and alkynes by ruthenium diphosphine complexes was proposed and discussed. The structures of two new complexes, $\mathrm{C}_{49} \mathrm{H}_{58} \mathrm{Cl}_{4} \mathrm{P}_{2} \mathrm{Ru}_{2}$ and $\mathrm{C}_{35} \mathrm{H}_{36} \mathrm{Cl}_{2} \mathrm{P}{ }_{2} \mathrm{Ru}$, as hydroamination catalysts were determined by $\mathrm{X}$-ray crystallography.
\end{abstract}

Keywords Ruthenium complexes - Diphosphine ligands . Hydroamination · Homogeneous catalyst

\section{Introduction}

There are considerable interests in the development of efficient synthetic protocols for the construction of carbon-

B. Tamaddoni Jahromi · A. Nemati Kharat ( $₫)$

School of Chemistry, University College of Science,

University of Tehran, Tehran, Iran

e-mail: alnema@khayam.ut.ac.ir

M. M. Amini - H. Khavasi

Department of Chemistry, Shahid Beheshti University,

Tehran, Iran nitrogen bonds because of their importance as fine chemicals, pharmacological, dyes and natural products [1]. Among the various organic transformations, the direct addition of $\mathrm{N}-\mathrm{H}$ bonds to alkenes and alkynes is a challenging and highly desirable reaction [2]. In this respect, the transition metal-catalyzed hydroamination of olefins has been developed as an important tool for selective production of a large variety of amines and imines. Industrially important terminal olefins provide two regioisomeric amines, the Markovnikov and anti-Markovnikov products. The Markovnikov regioisomer is usually favored as a consequence of the higher stability of the intermediate [3]. Different types of transition metal complexes [4, 5], strong bases [6] and various acids [7], have been used as the catalyst for hydroamination reactions. Despite considerable progress in recent years, a general hydroamination protocol for olefins has not yet been developed. To catalyze the hydroamination of alkenes or alkynes, two basic approaches have been used: activation of either the amine by low-valent transition metal complexes or the unsaturated bond by high-valent complexes. Since it is possible to change the properties of the catalyst by simple ligand exchange reactions, transition metal complexes probably offer the most promising route for the development of a general and efficient catalytic hydroamination process [8]. The first transition metal catalysts for hydroamination were rhodium complexes, introduced by Du Pont for the reaction of ethylene with secondary amines [9]. Subsequently, Taube et al. [10-12] elucidated the mechanism of this reaction and synthesized more active rhodium catalysts. Milstein et al. [13] showed that, in addition to the rhodium complexes, iridium complexes are also active for hydroamination reactions.

Hartwig et al. [14, 15] recently reported a significantly improved catalyst, generated from $\left[\mathrm{Pd}\left(\mathrm{PPh}_{3}\right)_{4}\right]$ and 
$\mathrm{CF}_{3} \mathrm{CO}_{2} \mathrm{H}$, at room temperature, however, even in this case, the reaction takes about a day for completion. Since the 1990s, ruthenium-catalyzed reactions such as [16] olefin metathesis [17], the oxidation of alcohols and amines [18], asymmetric reduction using hydrogen [19], hydroamination and hydroaminomethylation of olefins have attracted a great interest in organic synthesis [20]. Among these complexes, half-sandwich ruthenium(II) arenes are important and widely used organometallic compounds and exhibit a diverse range of coordination chemistry [21-24].

While applications of bidentate phosphine ligands are prevalent in the coordination chemistry of the transition metals, it is interesting to note that the actual process of forming these complexes has received relatively little attention.

As a continuation of our studies on these systems, we thought it is worth taking a detailed study of the reactivity of ruthenium-arene with bidentate phosphine ligands. In this context, we have prepared several ruthenium(II) complexes with diphosphines ligands, diphenylphosphinomethane (dppm), diphenylphosphinoethane (dppe), diphenylphosphinopropane (dppp), diphenylphosphinobutane (dppb) and diphenylphosphinopentane (dpppe), and studied their catalytic activities in hydroamination of cycloolefins and alkynes. Furthermore, the crystal structure of two new complexes $\left[\mathrm{Ru}(\mathrm{cymene}) \mathrm{Cl}_{2} \mathrm{dppm}\right]_{2}$ and $[\mathrm{Ru}(\mathrm{cy}-$ mene) $\mathrm{Cl}_{2}$ dpppe $]_{2}$, were determined by X-ray diffraction analysis.

\section{Experimental}

\section{General}

All reactions were performed under nitrogen atmosphere using a nitrogen-filled glovebox or standard Schlenk techniques. All chemicals and reagents were purchased from Aldrich or Strem chemical companies. Amines were purified by distillation from the appropriate drying agents. All solvents were of analytical grade, and purified prior to use based on standard methods. Xantphos derivatives and $\left[\mathrm{Ru}(p \text {-cymene }) \mathrm{Cl}_{2}\right]_{2}$ were prepared according to previously published methods $[25,26]$. Melting points are uncorrected and were obtained with an Electrothermal 9200 melting point apparatus. ${ }^{1} \mathrm{H}$ and ${ }^{31} \mathrm{P}$ NMR spectra were recorded at room temperature in $\mathrm{CDCl}_{3}$ on a Bruker Avance $300 \mathrm{MHz}$ instrument. Single-crystal X-ray diffraction data were collected on a STOE IPDS-II diffractometer with graphite monochromated Mo $\mathrm{K}_{\alpha}$ radiation at room temperature using Stoe X-AREA software [27]. For monitoring of reaction products and their identity, a gas chromatograph, Agilent Technologies 7890A instrument (equipped with a HP-1 capillary column, a FID detector), and a mass

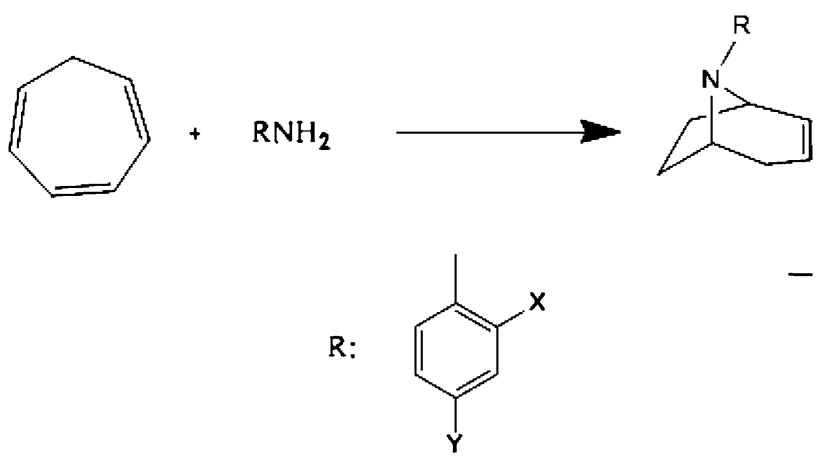

Scheme 1 Hydroamination of cycloheptatriene with substituted anilines

Table 1 Effect of different phosphine ligands on hydroamination of cycloheptatriene with substituted anilines

\begin{tabular}{llcc}
\hline Entry & Free ligand & Conversion $(\%)$ & TON \\
\hline 1 & No ligand & 0 & - \\
2 & $\mathrm{PPh}_{3}$ & 0 & - \\
3 & $\mathrm{Dppm}$ & 8 & 16 \\
4 & Dppe & 10 & 20 \\
5 & Dppp & 12 & 24 \\
6 & Dppb & 30 & 60 \\
7 & Dpppe & 42 & 84 \\
8 & Xantphos & 18 & 36 \\
9 & Xantphos=O & 25 & 50 \\
10 & Xantphos=S & 15 & 30 \\
11 & Xantphos=Se & 16 & 32 \\
\hline
\end{tabular}

Cycloheptatriene $(2 \mathrm{mmol})$, aniline $(1 \mathrm{mmol}),\left[\mathrm{Ru}(\mathrm{cymene}) \mathrm{Cl}_{2}\right]_{2}$ $(0.01 \mathrm{mmol})$, dpppe $(0.02 \mathrm{mmol})$, additive $(0.05 \mathrm{mmol})$, NMP $(2 \mathrm{ml})$, $T=140{ }^{\circ} \mathrm{C}$, TON calculated as mmol product $/ \mathrm{mmol}$ catalyst

spectroscope model $5975 \mathrm{C}$ with a triple-axis detector was used. Dodecane was used as internal standard.

General procedure for the synthesis of complexes

Dichloro( $p$-cymene)ruthenium(II) dimer, $[\mathrm{Ru}(p$-cymene) $\left.\mathrm{Cl}_{2}\right]_{2},(0.01 \mathrm{mmol})$ was dissolved in $(50 \mathrm{~mL})$ dichloromethane, then a solution of diphosphine, $(0.02 \mathrm{mmol})$ in dichloromethane $(50 \mathrm{~mL})$ was added drop wise and the mixture was refluxed for $2 \mathrm{~h}$. The resultant dark-red solution was filtered and the solvent was removed in reduced pressure. The resulting solid was re-dissolved in dioxane and was cooled to $-10{ }^{\circ} \mathrm{C}$. After several days, suitable crystals of ruthenium complex were collected.

\section{[Ru(cymene) $\left.\mathrm{Cl}_{2}\right]$ dppm (1)}

Yellow solid (yield $72 \%$ ). Anal. calc. for $\mathrm{C}_{35} \mathrm{H}_{36} \mathrm{Cl}_{2} \mathrm{P}_{2} \mathrm{Ru}_{1}$ : C, 60.87; H, 5.25. Found: C, 60.56; H, 5.11. ${ }^{31} \mathrm{P}\left\{{ }^{1} \mathrm{H}\right\}$-NMR $\left(\mathrm{CDCl}_{3}, \mathrm{ppm}\right): 26.3\left(\mathrm{Ph}_{2} \mathrm{PCH}_{2} \mathrm{PPh}_{2}\right) 27.4\left(\mathrm{Ph}_{2} \mathrm{PCH}_{2} \mathrm{PPh}_{2}\right)$. 
Table 2 Hydroamination of cycloheptatriene with aniline derivatives

\begin{tabular}{|c|c|c|c|}
\hline Additive (acid/base) & Substrate & Conversion $(\%)$ & TON \\
\hline- & $\mathrm{H}$ & 33 & 66 \\
\hline TFA & $\mathrm{H}$ & 38 & 76 \\
\hline TEA & $\mathrm{H}$ & 41 & 82 \\
\hline- & $p-\mathrm{OH}$ & 35 & 70 \\
\hline TFA & $p-\mathrm{OH}$ & 43 & 86 \\
\hline TEA & $p-\mathrm{OH}$ & 54 & 108 \\
\hline- & $m-\mathrm{OH}$ & 32 & 64 \\
\hline TFA & $m-\mathrm{OH}$ & 35 & 70 \\
\hline TEA & $m-\mathrm{OH}$ & 42 & 84 \\
\hline- & $p$-OMe & 44 & 88 \\
\hline TEA & $p$-OMe & 51 & 102 \\
\hline TFA & $p$-OMe & 63 & 126 \\
\hline- & $m$-OMe & 51 & 102 \\
\hline TEA & $m$-OMe & 60 & 120 \\
\hline TFA & $m$-OMe & 56 & 112 \\
\hline- & $p$-Me & 37 & 74 \\
\hline TFA & $p$-Me & 42 & 84 \\
\hline TEA & $p$-Me & 50 & 100 \\
\hline- & $m-\mathrm{Me}$ & 21 & 42 \\
\hline TFA & $m$-Me & 36 & 72 \\
\hline TEA & $m-\mathrm{Me}$ & 44 & 88 \\
\hline- & $p-\mathrm{NO}_{2}$ & 13 & 26 \\
\hline TFA & $p-\mathrm{NO}_{2}$ & 17 & 34 \\
\hline TEA & $p-\mathrm{NO}_{2}$ & 19 & 38 \\
\hline- & $m-\mathrm{NO}_{2}$ & 15 & 30 \\
\hline TEA & $m-\mathrm{NO}_{2}$ & 20 & 40 \\
\hline TFA & $m-\mathrm{NO}_{2}$ & 18 & 36 \\
\hline- & $p-\mathrm{Cl}$ & 15 & 30 \\
\hline TEA & $p-\mathrm{Cl}$ & 20 & 40 \\
\hline TFA & $p-\mathrm{Cl}$ & 17 & 34 \\
\hline- & $m-\mathrm{Cl}$ & 13 & 26 \\
\hline TEA & $m-\mathrm{Cl}$ & 19 & 38 \\
\hline TFA & $m-\mathrm{Cl}$ & 16 & 32 \\
\hline
\end{tabular}

Cycloheptatriene $(2 \mathrm{mmol})$, aniline $(1 \mathrm{mmol}),\left[\mathrm{Ru}(\text { cymene }) \mathrm{Cl}_{2}\right]_{2}$ (0.01 mmol), dpppe (0.02 mmol), additive (0.05 mmol), NMP (2 ml), $T=140{ }^{\circ} \mathrm{C}$, TON is calculated as mmol product $/ \mathrm{mmol}$ catalyst

${ }^{1} \mathrm{HNMR} \quad\left(\mathrm{CDCl}_{3}, \quad\right.$ ppm$): \quad 6.99-7.95 \quad\left(\mathrm{~m}, \quad 20 \mathrm{H}, \mathrm{C}_{6} \mathrm{H}_{5}\right)$, 5.14-5.32 (d, 4H, $\left.\quad \mathrm{C}_{6} \mathrm{H}_{4}\right) \quad 3.40-3.44 \quad(\mathrm{dd}, \quad 2 \mathrm{H}$, $\mathrm{Ph}_{2} \mathrm{PCH}_{2} \mathrm{PPh}_{2}$ ), 2.48 (hept, $\left.1 \mathrm{H}, \mathrm{CH}\left(\mathrm{CH}_{3}\right)_{2}\right), 1.87$ (s, 3H, C$\left.\mathrm{CH}_{3}\right), 0.76\left(\mathrm{~d}, 6 \mathrm{H}, \mathrm{CH}\left(\mathrm{CH}_{3}\right)_{2}\right)$.

\section{$\mathrm{Ru}$ (cymene) $\left.\mathrm{Cl}_{2}\right]_{2}$ dppe (2)}

Yellow solid (yield $68 \%$ ). Elemental anal. calc. for $\mathrm{C}_{46} \mathrm{H}_{52} \mathrm{Cl}_{4} \mathrm{P}_{2} \mathrm{Ru}_{2}$ : C, 54.66; H, 5.19 Found: C, 54.56; H, 5.12, ${ }^{31} \mathrm{P}\left\{{ }^{1} \mathrm{H}\right\}$-NMR $\left(\mathrm{CDCl}_{3}, \delta\right): 22.5\left(\mathrm{~s}, \mathrm{PPh}_{2}\right) .1 \mathrm{H} \mathrm{NMR}\left(\mathrm{CDCl}_{3}\right.$,

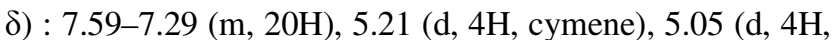
cymene), 2.43 ( $\mathrm{m}, 4 \mathrm{H}$, dppe), 2.37 (sept, $2 \mathrm{H}, \mathrm{CHMe}_{2}$ ), 1.75 (s, $6 \mathrm{H}, p$-cymene- $\left.\mathrm{CH}_{3}\right), 0.82\left(\mathrm{~d}, 12 \mathrm{H}, \mathrm{CH}\left(\mathrm{CH}_{3}\right)_{2}\right.$.

\section{[Ru(cymene) $\left.\mathrm{Cl}_{2}\right]_{2} d p p p(3)$}

Yellow solid (yield $60 \%$ ), Elemental anal. calc. for $\mathrm{C}_{47} \mathrm{H}_{54} \mathrm{Cl}_{4} \mathrm{P}_{2} \mathrm{Ru}_{2}$ : C, 55.08; H, 5.31 Found: C, 55.00; $\mathrm{H}$, 5.28. ${ }^{31} \mathrm{P}\left\{{ }^{1} \mathrm{H}\right\}-\mathrm{NMR}\left(\mathrm{CDCl}_{3}, \mathrm{ppm}\right): 24.5\left(\mathrm{~s}, \mathrm{PPh}_{2}\right) .{ }^{1} \mathrm{H}$ NMR $\left(\mathrm{CDCl}_{3}, \mathrm{ppm}\right): 7.3-7.6\left(\mathrm{~m}, 20 \mathrm{H}, \mathrm{C}_{6} \mathrm{H}_{5}\right), 4.9-5.13(\mathrm{~m}$, $8 \mathrm{H}, p$-cymene-CH), 2.30 (sept, $2 \mathrm{H}, \mathrm{CHMe}_{2}$ ), 2.14 (br, $6 \mathrm{H}$, dppp- $\left.\mathrm{CH}_{2}\right), 1.71\left(\mathrm{~s}, 6 \mathrm{H}, p\right.$-cymene- $\left.\mathrm{CH}_{3}\right), 0.67(\mathrm{~d}, 12 \mathrm{H}, p$ cymene- $\mathrm{CHMe}_{2}$ ).

\section{[Ru(cymene) $\left.\mathrm{Cl}_{2}\right]_{2} d p p b(4)$}

Yellow solid (yield $65 \%$ ), Elemental anal. calc. for $\mathrm{C}_{48} \mathrm{H}_{56} \mathrm{Cl}_{4} \mathrm{P}_{2} \mathrm{Ru}_{2}: \mathrm{C}, 55.49 ; \mathrm{H}, 5.43$ Found: C, 55.45; H, 5.40. ${ }^{31} \mathrm{P}\left\{{ }^{1} \mathrm{H}\right\}$-NMR $\left(\mathrm{CDCl}_{3}, \mathrm{ppm}\right): 24.9\left(\mathrm{~s}, \mathrm{PPh}_{2}\right) .{ }^{1} \mathrm{H}$ NMR $\left(\mathrm{CDCl}_{3}, \mathrm{ppm}\right): 7.5\left(\mathrm{~m}, 8 \mathrm{H}, \mathrm{C}_{6} \mathrm{H}_{5}\right), 7.38(\mathrm{~m}, 12 \mathrm{H}$, $\mathrm{C}_{6} \mathrm{H}_{5}$ ), 5.11 (d, 4H, p-cymene-CH), 4.94 (d, 4H, p-cymene-CH), 2.25 (sept, $2 \mathrm{H}, \mathrm{CHMe}_{2}$ ), 2.10 (br, 4H, dppb$\mathrm{CH}_{2}$ ), 1.71 (s, 6H, p-cymene- $\mathrm{CH}_{3}$ ), 0.83 (br, 4H, dppb$\left.\mathrm{CH}_{2}\right) 0.70\left(\mathrm{~d}, 12 \mathrm{H}, p\right.$-cymene-CHMe $\left.{ }_{2}\right)$.

\section{[Ru(cymene) $\left.\mathrm{Cl}_{2}\right]_{2}$ dpppe (5)}

Orange solid (yield $76 \%$ ), Elemental anal. calc. for $\mathrm{C}_{49}$ $\mathrm{H}_{58} \mathrm{Cl}_{4} \mathrm{P}_{2} \mathrm{Ru}_{2}$ : C, 55.90; $\mathrm{H}, 5.55$. Found: $\mathrm{C}, 55.46 ; \mathrm{H}$, 5.43. ${ }^{31} \mathrm{P}\{1 \mathrm{H}\}-\mathrm{NMR}\left(\mathrm{CDCl}_{3}, \mathrm{ppm}\right): 26.2\left(\mathrm{~s}_{2} \mathrm{PPh}_{2}\right) .{ }^{1} \mathrm{H}$ NMR $\left(\mathrm{CDCl}_{3}, \mathrm{ppm}\right): 7.6\left(\mathrm{~m}, 8 \mathrm{H}, \mathrm{C}_{6} \mathrm{H}_{5}\right), 7.2(\mathrm{~m}, 12 \mathrm{H}$, $\left.\mathrm{C}_{6} \mathrm{H}_{5}\right), 5.31(\mathrm{~d}, 4 \mathrm{H}, p$-cymene-CH), $4.6(\mathrm{~d}, 4 \mathrm{H}, p$-cymene$\mathrm{CH}$ ), 2.3 (sept, $2 \mathrm{H}, \mathrm{CHMe}_{2}$ ), 2.15 (br, 4H, dpppe- $\mathrm{CH}_{2}$ ), 1.51 (s, $6 \mathrm{H}, p$-cymene- $\left.\mathrm{CH}_{3}\right) 1.2-0.9$ (br, $6 \mathrm{H}$, dpppe- $\mathrm{CH}_{2}$ ) $0.72(\mathrm{~d}, 12 \mathrm{H}, p$-cymene-CHMe 2$)$.

General procedure for the hydroamination of substituted anilines with cycloheptatriene

Dichloro(p-cymene)ruthenium(II) dimer (2 mol\%, $0.01-$ $0.02 \mathrm{mmol}$ ), diphosphine ligand (4 mol\%, 0.02-0.04 $\mathrm{mmol})$, and base additive (10 $\mathrm{mol} \%, 0.05-0.10 \mathrm{mmol})$ were added directly into a 5-mL stainless steel autoclave. Required amount of cycloheptatriene and substituted aniline dissolved in $2 \mathrm{~mL} N$-methyl pyrrolidine were added and the reaction mixture was flushed with argon for $5 \mathrm{~min}$, then it was stirred at $140{ }^{\circ} \mathrm{C}$ for $72 \mathrm{~h}$. Reaction products were analyzed by gas chromatography after addition of dodecane $(0.15-0.20 \mathrm{mmol})$ as internal standard.

General procedure for the hydroamination of substituted anilines with phenylacetylene

The autoclave was charged with $\left[\mathrm{Ru}(\text { cymene }) \mathrm{Cl}_{2}\right]_{2}$ $(0.05 \mathrm{mmol})$, diphosphine ligand $(4 \mathrm{~mol} \%, \quad 0.02-$ $0.04 \mathrm{mmol})$, substituted aniline $(1 \mathrm{mmol})$, phenylacetylene (1 mmol) and $2 \mathrm{ml} \mathrm{N}$-methyl pyrrolidine as solvent. The 
Scheme 2 Proposed mechanism for hydroamination of cycloheptatriene with aniline

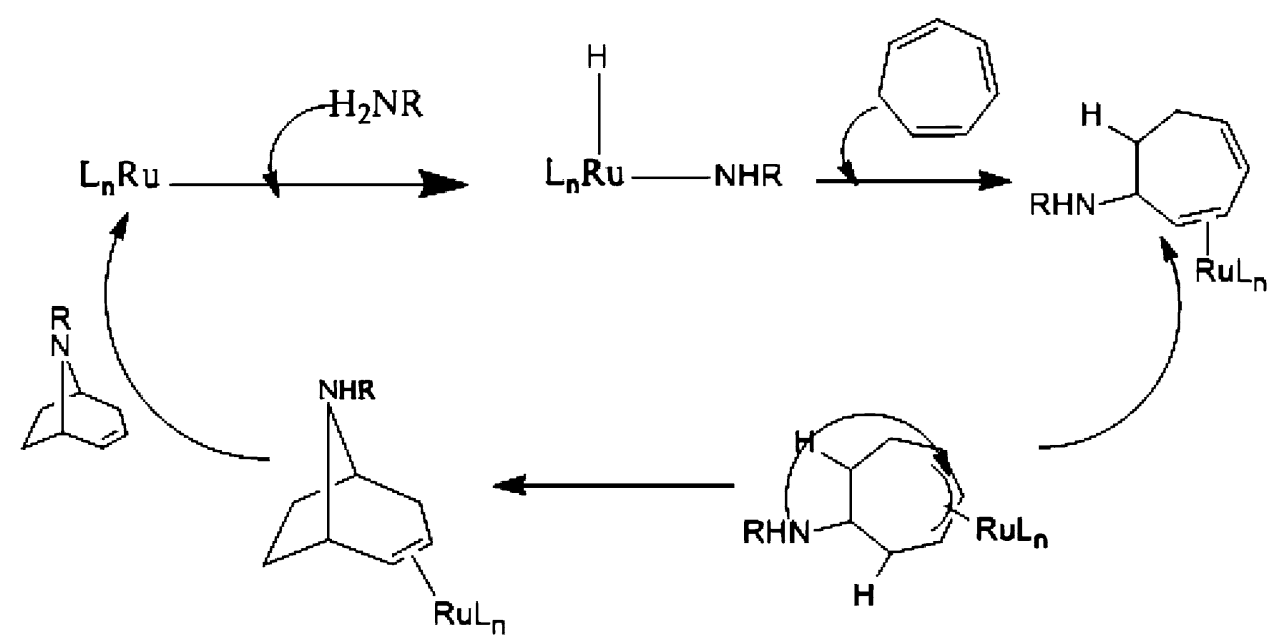

Scheme 3 Reaction of phenylacetylene with substituted aniline<smiles>C#Cc1ccccc1</smiles><smiles>[X]c1ccc(NC(=C)c2ccccc2)c([X])c1</smiles>

autoclave was flushed with argon for 5 min and then it was stirred at $130{ }^{\circ} \mathrm{C}$. After $16 \mathrm{~h}$, the autoclave was cooled to room temperature and the products were analyzed by gas chromatography.

\section{Result and discussion}

\section{Catalytic studies}

Pioneer works of Robinson [28] opened a new route for preparation of biological active chemicals from simple raw materials. Catalytic hydroamination of cycloheptatriene with amines is an alternative method for making tropene rings and become attractive in the recent years. In this work, tropene ring was formed in the hydroaminations of cycloheptatriene with aniline derivatives (Scheme 1) in the presence of the catalytic amount of ruthenium complexes and dpppe with an isolation yield of $60 \%$. We proposed that these catalyst precursors generate a diphosphine complex which is active in this reaction. In this context, a series of ruthenium-arene diphosphine complexes have been synthesized from the appropriate dimer, $\left[\left\{\mathrm{Ru}(\text { arene }) \mathrm{Cl}_{2}\right\}_{2}\right]$. Ruthenium(II) complexes of diphosphines, diphenylphosphinomethane (dppm) (1), diphenylphosphinoethane (dppe)
(2), diphenylphosphinopropane (dppp) (3), diphenylphosphinobutane (dppb) (4) and diphenylphosphinopentane (dpppe) (5) were prepared. The prepared complexes were applied for catalytic hydroamination of cycloheptatriene with substituted anilines (Scheme 1).

Results of hydroamination of cycloheptatriene with substituted anilines in the presence of different ligands are summarized in Table 1 . The reactions were typically carried out at $140{ }^{\circ} \mathrm{C}$ with $0.5-1 \mathrm{mmol}$ aniline and $2-4 \mathrm{mmol}$ of triene. As can be seen in Table 1, dpppe shows a higher conversion with respect to other diphosphine ligands, xantphos calcogenides and monophosphine ligands.

The results of hydroamination of cycloheptatriene with aniline derivatives are listed in Table 2. As expected the electron donating functional groups on aniline increased the activity of the hydroamination reaction.

Proposed mechanism [29] suggests that a ligand leaves the ruthenium center at the first stage. Subsequently, oxidative addition of an amine to coordinatively unsaturated ruthenium center takes place (Scheme 2). Apparently, $\mathrm{Ru}$ (II) precursors, at first stage reduces to a low-valent catalytically active $\mathrm{Ru}(0)$ species under reaction conditions and then a nucleophilic attack of amine on ruthenium generates a complex containing an amino group and this followed up by addition of cycloheptatriene. Dissociation 
Table 3 Reaction of phenylacetylene with aniline derivatives

\begin{tabular}{|c|c|c|c|c|}
\hline Additive & Substrate & $\begin{array}{l}\text { Conversion } \\
(\%)\end{array}$ & TON & $\begin{array}{l}\text { Ratio of products } \\
\text { anti-Markovnikov/ } \\
\text { Markovnikov }\end{array}$ \\
\hline- & $\mathrm{H}$ & 61 & 122 & 2.6 \\
\hline TEA & $\mathrm{H}$ & 72 & 144 & 4.1 \\
\hline TFA & $\mathrm{H}$ & 68 & 136 & 2.7 \\
\hline- & $p$-OMe & 70 & 140 & 2.4 \\
\hline TEA & $p$-OMe & 82 & 164 & 3.9 \\
\hline TFA & $p$-OMe & 74 & 148 & 2.8 \\
\hline- & $m$-OMe & 65 & 130 & 2.7 \\
\hline TEA & $m$-OMe & 79 & 158 & 4 \\
\hline TFA & $m$-OMe & 75 & 150 & 3.3 \\
\hline- & $p-\mathrm{OH}$ & 53 & 106 & 2.9 \\
\hline TEA & $p-\mathrm{OH}$ & 60 & 120 & 4.1 \\
\hline TFA & $p-\mathrm{OH}$ & 55 & 110 & 3.2 \\
\hline- & $m-\mathrm{OH}$ & 58 & 116 & 2.6 \\
\hline TEA & $m-\mathrm{OH}$ & 65 & 130 & 4.4 \\
\hline TFA & $m-\mathrm{OH}$ & 61 & 122 & 3.4 \\
\hline- & $p$-Me & 50 & 100 & 2.6 \\
\hline TEA & $p$-Me & 80 & 160 & 4.6 \\
\hline TFA & $p$-Me & 65 & 130 & 3.4 \\
\hline- & $m$-Me & 48 & 96 & 2.8 \\
\hline TEA & $m$-Me & 77 & 154 & 4.5 \\
\hline TFA & $m$-Me & 63 & 126 & 3.9 \\
\hline- & $p-\mathrm{NO}_{2}$ & 45 & 90 & 2.6 \\
\hline TEA & $p-\mathrm{NO}_{2}$ & 58 & 116 & 4.3 \\
\hline TFA & $p-\mathrm{NO}_{2}$ & 50 & 100 & 3.5 \\
\hline- & $m-\mathrm{NO}_{2}$ & 43 & 86 & 2.3 \\
\hline TEA & $m-\mathrm{NO}_{2}$ & 55 & 110 & 4.5 \\
\hline TFA & $m-\mathrm{NO}_{2}$ & 50 & 100 & 3.7 \\
\hline TEA & $o$-OMe, $p$-OMe & 66 & 132 & 5 \\
\hline TEA & $o$-Me, $p$-Me & 67 & 134 & 4.6 \\
\hline
\end{tabular}

Phenylacetylene $(2 \mathrm{mmol})$, aniline derivative $(1 \mathrm{mmol})$, [Ru(cymene $\left.\mathrm{Cl}_{2}\right]_{2}$ (0.01 $\left.\mathrm{mmol}\right)$, dpppe $(0.02 \mathrm{mmol})$, additive $(0.05 \mathrm{mmol})$, NMP $(2 \mathrm{ml}), T=140{ }^{\circ} \mathrm{C}, t=19 \mathrm{~h}$. TON is calculated as mmol products/mmol catalyst

of the product and proton transfer to the combination of ruthenium and triene would then regenerate the pentadienyl intermediate.

According to above mechanism, reduction of the electron density in the aniline ring by incorporation of an electron withdrawing group like chloro or nitro decreases the yield of the reaction. Recall that meta substituents only contribute inductive effects, whereas para substituents contribute both inductive and resonance effects, thus in the case of methoxy and hydroxy groups in ortho and para position, the lone pair of electrons on the oxygen can donate back into the aryl ring by resonance giving rise to a strong electron donating effect. Other substituents, such as methyl, may also donate electron density to the $\pi$ system;
Table 4 Catalytic hydroamination of different amines with cycloheptatriene and phenylacetylene

\begin{tabular}{lllll}
\hline Substrate & $\begin{array}{l}\text { Conversion } \\
(\%)^{\mathrm{a}}\end{array}$ & $\mathrm{TON}^{\mathrm{a}}$ & $\begin{array}{l}\text { Conversion } \\
(\%)^{\mathrm{b}}\end{array}$ & $\mathrm{TON}^{\mathrm{b}}$ \\
\hline Benzylamine & 37 & 75 & 77 & 154 \\
Cyclohexylamine & 31 & 62 & 75 & 150 \\
Phenylethylamine & 32 & 64 & 84 & 168 \\
Octylamine & $27^{*}$ & 27 & 88 & 176 \\
Hexylamine & $25^{*}$ & 25 & 79 & 158 \\
$N$-Butylamine & $21^{*}$ & 21 & 71 & 142 \\
Isopropylamine & $20^{*}$ & 20 & 68 & 136 \\
\hline
\end{tabular}

$\left[\mathrm{Ru}(\mathrm{cymene}) \mathrm{Cl}_{2}\right]_{2}(0.01 \mathrm{mmol}), *(0.02 \mathrm{mmol})$, dpppe $(0.02 \mathrm{mmol})$, aniline derivative $(1 \mathrm{mmol})$, TEA $(0.05 \mathrm{mmol})$, NMP $(2 \mathrm{ml}), T=$ $140{ }^{\circ} \mathrm{C}$

${ }^{a}$ Cycloheptatriene, $72 \mathrm{~h}$

b Phenylacetylene, $19 \mathrm{~h}$

TON is calculated as mmol product/mmol catalyst

however, since they lack an available unshared pair of electrons, their ability is rather limited, thus they only weakly activate the ring.

Because of importance of solvent on conversion and chemoselectivity of hydroamination reactions different solvents such as toluene, tetrahydrofuran, dioxane and $\mathrm{N}$ methyl pyrrolidine were used. With toluene as a nonpolar aprotic solvent, in general higher temperature is required; however, the yield is lower compared to tetrahydrofuran and dioxane. Notably, donor solvents accelerate hydroamination reactions and even in protic solvents amines add spontaneously to electron deficient alkenes [30]. Furthermore, $N$-methyl pyrrolidine as a reaction medium increased the overall rate of reaction which probably is due to its ability for reduction of metallic complexes [31], its higher boiling point and its basic character. Most hydroamination reactions have very high activation energies; however, the use of the basic or acidic additives can promote the reaction. According to the earlier reports [32, 33], the selectivity for hydroamination of dienes can be controlled via addition of acids to the catalytic system. Among the acidic additives, such as trifluoromethanesulfonic acid, $p$-toluenesulfonic acid and trifluoro acetic anhydride, OTf ${ }^{-}$ showed the best activity in this work. Basic co-catalysts such as potassium carbonate and triethylamine showed higher conversion than the acidic ones due to the higher nucleophilicity power of amines. Considering the above data, the best catalytic performance for hydroamination of cycloheptatriene is achieved by using an aniline with an electron donating group, dpppe as supporting ligand and triethylamine in $\mathrm{N}$-methyl pyrrolidine as solvent.

Using above strategy, ketimines as an important class of compounds in organic synthesis, can be prepared from catalytic hydroamination reactions. The hydroamination of 
Fig. 1 Ortep view of $\mathrm{Ru}($ cymene $) \mathrm{Cl}_{2}(\mathrm{dppm})$ for $50 \%$ ellipsoid

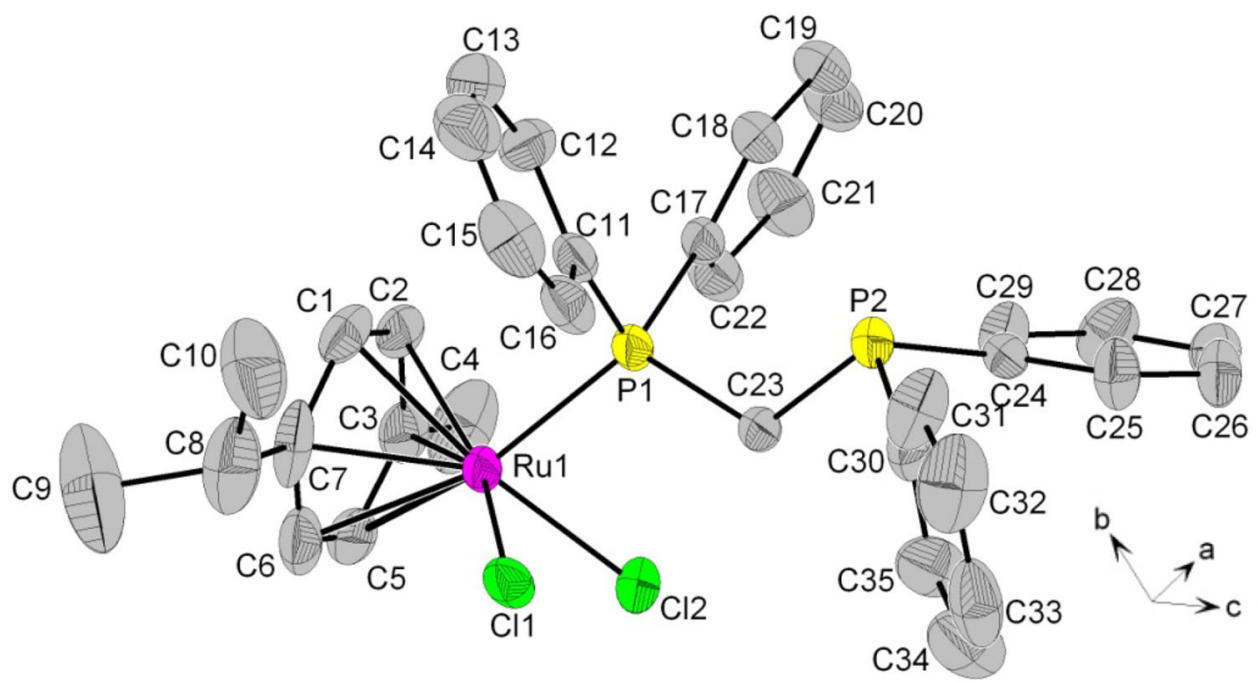

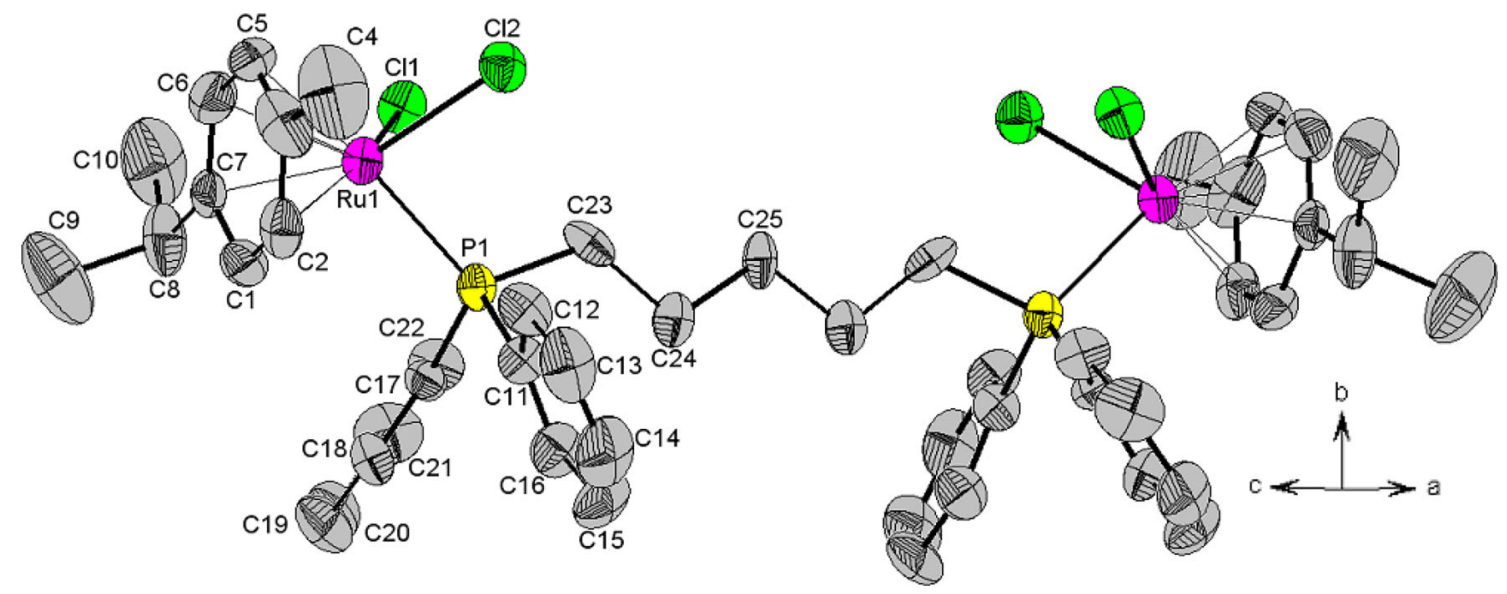

Fig. 2 Ortep view of $\left[\mathrm{Ru}(\mathrm{cymene}) \mathrm{Cl}_{2}(\mathrm{dpppe})\right]_{2}$ for $50 \%$ ellipsoid

the terminal alkynes with anilines using a ruthenium carbonyl catalyst was reported in the literature [34]. Herein, we disclose hydroamination of phenylacetylene with aniline derivatives using above high reactive catalytic system (Scheme 3).

The results are depicted in Table 3. Because of higher reactivity of phenylacetylene, conversion up to $80 \%$ was obtained using dpppe, $\left[\mathrm{Ru}(\mathrm{cymene}) \mathrm{Cl}_{2}\right]_{2}$ and triethylamine (TEA) as cocatalyst.

Two observed products are associated with Markovnikov and the anti-Markovnikov additions. The reactions that were conducted with disubstituted anilines produced lower amounts of the side products, presumably due to statistical reasons and steric hindrance toward reaction at the ortho position of the aryl ring. Besides for substituted anilines, this catalytic system was also utilized in other aliphatic and aromatic amines and the results are illustrated in Table 4 . Notably, yield was lower in addition of aliphatic amines to cycloheptatriene at $140{ }^{\circ} \mathrm{C}$ in the presence of higher quantities of catalyst and triethylamine.

Characterization of complexes

In this work, activity of a series of ruthenium-arene diphosphine catalysts have been measured. The characters of active catalysts were investigated and among them, structures of two new complexes, $\mathrm{Ru}($ cymene $) \mathrm{Cl}_{2}(\mathrm{dppm})$ (1) and $\left[\mathrm{Ru} \text { (cymene) } \mathrm{Cl}_{2} \text { (dpppe) }\right]_{2}$ (5), were determined by single-crystal X-ray diffraction. The formation of these complexes is usually accompanied by the formation of dimeric ruthenium species, However, in the case of the reaction between dppm and $\left[(p \text {-cymene }) \mathrm{RuCl}_{2}\right]_{2}$ in $1: 1 \mathrm{~mol}$ ratio the mononuclear complex $\left[\mathrm{Ru}\left(\mathrm{C}_{10} \mathrm{H}_{14}\right) \mathrm{Cl}_{2}(\mathrm{dppm})\right]$ was isolated in which the ${ }^{31} \mathrm{P}$ NMR spectrum shows two peaks at chemical shift of 26.3 and $27.4 \mathrm{ppm}$, and demonstrating the uncommon $\mu^{1}$-dppm coordination mode 
[35]. The chemical shift of $26.2 \mathrm{ppm}$ in the ${ }^{31} \mathrm{P}$ NMR spectrum of $\left[\text { (cymene) } \mathrm{RuCl}_{2}\right]_{2}$ (dpppe) is similar to that of $24.8 \mathrm{ppm}$ reported for $\left[(\mathrm{cymene}) \mathrm{RuCl}_{2}\right]_{2}(\mathrm{dppb})$ [36], proving it is in dimeric structure.

These complexes are air stable and soluble in most organic solvents. Suitable crystals of complexes were obtained by slow evaporation from dioxane. Ortep view of complexes $\mathbf{1}$ and $\mathbf{5}$ are depicted in Figs. 1 and 2, respectively. The structures of two complexes are similar to previously reported ruthenium(II) complexes of diphosphines [36-39]. Single crystal structure of $\mathbf{1}$ confirmed the four-coordinate geometry with two chlorine ion and cymene ligand which is connected through $\pi$-electrons of $\mu^{6}$ cymene and one phosphor of dppm ligand in the complex.

Complex $\mathrm{Ru}($ cymene $) \mathrm{Cl}_{2}(\mathrm{dppm})$ crystallizes as orange cubes in the triclinic space group $P-1$ with two molecules in the unit cell. The ruthenium-P bond distance is $2.3515 \AA$ comparable with reported bond lengths for a four-coordinate ruthenium complex [37]. The $\mathrm{RuCl}(1)$ and $\mathrm{RuCl}(2)$ distances in 1 are 2.4063(16) and 2.4177(13) $\AA$, respectively. The weak hydrogen bonds that exist in the structure, stabilized the packing of the complex (Fig. S1).

Furthermore, hydrogen bonds exist between the $\mathrm{C}-\mathrm{H}$ bond of cymene group and chloride ions of the next molecule $(\mathrm{C}(5)-\mathrm{H}(5) \cdots \mathrm{Cl}(1)=2.727 \AA$ with an angle of $150.92^{\circ}$ and $\mathrm{C}(6)-\mathrm{H}(6) \cdots \mathrm{Cl}(2)=2.770 \AA$ with an angle of $\left.166.41^{\circ}\right)$. The molecular structure of $[\mathrm{Ru}(\mathrm{cyme}-$ ne) $\mathrm{Cl}_{2}$ (dpppe) $]_{2}$ clearly shows two ( $p$-cymene) $\mathrm{RuCl}_{2}$ fragments connected through a dpppe bridge in a piano stool configuration.

The two $\mathrm{Ru}-\mathrm{C}$ bonds that lie trans to the phosphorus atoms, namely, $\mathrm{Ru}-\mathrm{C}(6)(2.220(10) \AA)$ and $\mathrm{Ru}-\mathrm{C}(5)$ (2. $227(10) \AA$ ) are slightly longer than other $\mathrm{Ru}-\mathrm{C}$ bonds 2.164, $2.186 \AA$. Similar bond length patterns have previously been noticed for $\left[(p\right.$-cymene $\left.\left.\left.) \mathrm{RuCl}_{2}\right)\right]_{2}(\mathrm{dpppe})\right]$ and [(p-cymene $\left.) \mathrm{RuCl}_{2}-\left(\mathrm{PMePh}_{2}\right)\right]$ and attributed to the bondlengthening trans effect of the tertiary phosphine ligand $[36,38]$. The $p$-cymene ring is essentially planar and $\mathrm{C}-\mathrm{C}$ bond lengths in the ring are equal, there is no alternate short and long bond, which indicates that there is no electron localization. The $\mathrm{Ru}-\mathrm{Cl}(1)$ and $\mathrm{Ru}-\mathrm{Cl}(2)$ distances in 5 is, 2.409(2) and 2.421(2) $\AA$, respectively. These bond lengths are similar to bond length of $2.4195 \AA$ in other $\mathrm{Ru}$ (II) complexes [36]. Some weak hydrogen bonds exist in the structure, stabilizing the packing of the complex (Fig. S2). Furthermore, hydrogen bonds exist between the $\mathrm{C}-\mathrm{H}$ bond of cymene group and chloride ions of the next molecule $[\mathrm{C}(5)-\mathrm{H}(5) \cdots \mathrm{Cl}(1)=2.601 \AA$ with an angle of 171.00 and $\mathrm{C}(6)-\mathrm{H}(6) \cdots \mathrm{Cl}(2)=2.830 \AA$ with an angle of $\left.140.6^{\circ}\right]$.

Crystallographic data and selected bond lengths and angles for complex 1 and 5 are listed in Table 5 and Table S3, respectively.
Table 5 Crystallographic and structure refinement data of $\mathbf{1}$ and $\mathbf{5}$

\begin{tabular}{|c|c|c|}
\hline & Complex 1 & Complex 5 \\
\hline Formula & $\begin{array}{l}\text { C35 H36 Cl2 P2 } \\
\text { Ru1 }\end{array}$ & $\begin{array}{l}\text { C49 H58 Cl4 P2 } \\
\text { Ru2 }\end{array}$ \\
\hline Formula weight & 690.55 & 1052.83 \\
\hline Crystal system & Triclinic & Monoclinic \\
\hline Space group & $P-1$ & $C 2 / c$ \\
\hline$a / \AA$ & $10.7174(8)$ & $30.243(6)$ \\
\hline$b / \AA$ & $12.8924(13)$ & $15.5904(15)$ \\
\hline$c / \AA$ & $13.3915(12)$ & $24.929(4)$ \\
\hline$\alpha / /^{\circ} 90$ & $101.544(8)$ & 90.00 \\
\hline$\beta /^{\circ} 100.26$ & 95.617 & 142.332 \\
\hline$\gamma /{ }^{\circ} 90$ & $98.137(7)$ & 90.00 \\
\hline Volume $/ \AA^{3}$ & $1779.4(3)$ & $7182.7(19)$ \\
\hline $\mathrm{Z}$ & 2 & 4 \\
\hline Density $($ calcd)/g & 1.289 & 0.974 \\
\hline $\begin{array}{l}\theta \text { ranges for data } \\
\text { collection }\end{array}$ & 0.71073 & 0.71073 \\
\hline$F\left(\begin{array}{lll}0 & 0 & 0\end{array}\right)$ & 708 & 2152 \\
\hline $\begin{array}{l}\text { Absorption coefficient/ } \\
\mathrm{mm}^{-1}\end{array}$ & 0.701 & 0.635 \\
\hline Data collected & 7735 & 7845 \\
\hline Final $R 1, w R 2^{\text {a }}$ (obs. data) & $0.0788,0.1210$ & $0.0816,0.1797$ \\
\hline Final $R 1, w R 2^{\mathrm{a}}$ (all data) & $0.0582,0.1056$ & $0.0910,0.2056$ \\
\hline Goodness of fit on $F 2$ (S) & 0.817 & 0.919 \\
\hline
\end{tabular}

${ }^{\mathrm{a}} R 1=\Sigma\|F 0|-| F c\| / \Sigma|F 0| ; w R 2=[\Sigma(w(F 02-F c 2) 2) / \Sigma w(F 02) 2] 1 / 2$

\section{Conclusions}

Ruthenium diphosphine complexes mediate hydroamination reaction of aniline derivatives with cycloheptatriene and phenylacetylene. Our studies showed that temperature, solvent, electronic and steric properties of substituents and addition of acidic or basic additives have a strong impact on hydroamination reaction. Cycloheptatriene was hydroaminated selectively with production of a sole product. Modification of the catalyst to improve activity and selectivity for hydroamination of the alkynes are in progress.

\section{Supplementary material}

CCDC numbers 974631 and 974632 contains the supplementary crystallographic data for $\mathrm{C} 35 \mathrm{H} 36 \mathrm{Cl} 2 \mathrm{P} 2 \mathrm{Ru} 1$ and C49 H58 C14 P2 Ru2 catalysts, respectively. These data can be obtained free of charge via http://www.ccdc.cam.ac. uk/conts/retrieving.html, or from the Cambridge Crystallographic Data Center, 12 Union Road, Cambridge CB2 1EZ, UK; Fax: +44 1223336 033; or E-mail: deposit@ccdc.cam.ac.uk. 
Acknowledgments The authors gratefully acknowledge the financial support from the University of Tehran.

Open Access This article is distributed under the terms of the Creative Commons Attribution License which permits any use, distribution, and reproduction in any medium, provided the original author(s) and the source are credited.

\section{References}

1. Brunet J, Neibecker D, Niedercorn F (1989) J Mol Catal 49:235-259

2. Beller M, Müller TE (1998) Chem Rev 98:675-703

3. Herwig J, Müller TE, Thiel OR (1999) Chem Eur J 5:1306-1309

4. McGrane PL, Livinghouse $\mathrm{T}$ (1993) J Am Chem Soc 115:11485-11489

5. Baranger AM, Walsh PJ, Bergman RG (1993) J Am Chem Soc 115:2753-2763

6. Pez GP, Galle GE (1985) Pure Appl Chem 57:1917-1926

7. Lequitte M, Figueras F, Moreau C, Hub S (1996) J Cat 163:255-261

8. Brunet JJ, Commenges G, Neibecker D, Philippot K (1994) J Organomet Chem 469:221-228

9. Beller M, Eichberger M, Trauthwein H (1997) Angew Chem 109:2306-2308

10. Selent D, Scharfenberg-Pfeiffer D, Reck G, Taube R (1991) J Organomet Chem 415:417-423

11. Steinborn D, Dies B, Wagner I, Taube R (1989) Z Chem 29:333-334

12. Steinborn D, Taube R (1986) Z Chem 26:349-359

13. Casalnuovo AL, Calabrese JC, Milstein D (1989) J Am Chem Soc 110:6738-6744

14. Lber O, Kawatsura M, Hartwig JF (2001) J Am Chem Soc 123:4366-4367

15. Kawatsura M, Hartwig JF (2000) J Am Chem Soc 122:9546-9547

16. Noyori R (2002) Angew Chem Int Ed 41:2008-2022

17. Noyori R, Ohkuma T (2001) Angew Chem Int Ed 40:40-73
18. Sandoval CA, Ohkuma T, Muniz K, Noyori R (2003) J Am Chem Soc 125:13490-13503

19. Ameroso D, Fogg DE (2000) Macromolecules 33:2815-2818

20. Hii K, Li K (2003) Chem Commun. 1132-1133

21. Rigby JH, Kondratenko MA (2004) Organomet Chem 7:181-204

22. Noyori R, Hashiguchi S (1997) Acc Chem Res 30:97-102

23. Qiu L, Kwong Y, Wu J, Lam WH, Chan S, Yu WY, Li YM, Guo R, Zhou Z (2006) J Am Chem Soc 128:5955-5965

24. Dowson GR, Haddow MF, Lee J, Wingad RL, Wass DF (2013) Chem Int 52:9005-9008

25. Tamaddoni Jahromi B, Nemati Kharat A, Zamanian S, Bakhoda A, Mashayekh K, Khazaeli (2012) Appl Catal A 188:433-434

26. Fackler JP (1982) Inorganic syntheses. Wiley, New York

27. X-STEP32, Version1.07b (2000) Stoe \& Cie, Darmstadt, Germany

28. Robinson R (1917) J Chem Soc Trans. 762-768

29. Johns AM, Utsunomiya M, Incarvito CD, Hartwig JF (2006) J Am Chem Soc 128:8134-8135

30. Smith AR, Lovick HM, Livinghouse T (2012) Tetrahedron Lett 53:6358-6360

31. Jeon SH, Xu P, MacK NH, Chiang LY, Brown L, Wang HL (2010) J Phys Chem C 114:36-40

32. Kiji J, Yamamoto K, Sasakawa E, Furukawa J (1973) J Chem Soc Chem Commun, pp 770-778

33. Dzhemilev UM, Yakupova AZ, Tolstikov GA (1976) Izv Akad Nauk SSSR Ser Khim, pp 1795-1798

34. Tokunaga M, Eckert M, Wakatsuki Y (1999) Angew Chem Int Ed 38:3222-3225

35. Gupta DK, Sahay AN, Pandey DS, Jha NK, Sharma P, Espinosa G, Cabrera A, Puerta MC, Valerga P (1998) J Organomet Chem 568:13-20

36. Doherty S, Knight J, Rath RK, Clegg W, Harrington RW, Newman CR, Campbell R, Amin H (2005) Organometallics 24:2633-2644

37. Daguenet C, Scopelliti R, Dyson PJ (2004) Organometallics 23:4849-4857

38. Bennett MA, Robertson GB, Smith AK (1972) J Organomet Chem 43:C41-C43

39. Chaplin AB, Fellay C, Laurenczy G, Dyson PJ (2007) Organometallics 26:586-593 